\title{
Research Article \\ Design Aspects of Printed Monopole Antennas for Ultra-Wide Band Applications
}

\author{
K. P. Ray \\ SAMEER, IIT Campus, Hill Side, Powai, Mumbai 400076, India \\ Correspondence should be addressed to K. P. Ray, kpray@rediffmail.com
}

Received 21 May 2007; Accepted 19 January 2008

Recommended by Hans G. Schantz

This paper presents the design equations for lower band-edge frequency for all the regular shapes of printed monopole antennas with various feed positions. The length of the feed transmission line is a critical design parameter of these monopole antennas. Design curves for the length of the feed transmission line for various lower band-edge frequencies for all these regular shaped monopoles have been generated. A systematic study has been presented to explain the ultra-wide bandwidth obtained from these antennas with an example of elliptical monopole antenna.

Copyright (C) 2008 K. P. Ray. This is an open access article distributed under the Creative Commons Attribution License, which permits unrestricted use, distribution, and reproduction in any medium, provided the original work is properly cited.

\section{INTRODUCTION}

Present time is witnessing a very rapid growth of wireless communications, for which antennas with very large bandwidth are in strong demand, so that various applications are covered with fewer or preferably with a single antenna. It will be preferred that an antenna has bandwidth in excess of frequency range from $800 \mathrm{MHz}$ to $11 \mathrm{GHz}$ or even more, to include all the existing wireless communication systems such as AMPC800, GSM900, GSM1800, PCS1900, WCDMA/UMTS (3G), 2.45/5.2/5.8-GHz-ISM, UNII, DECT, WLANs, European Hiper LAN I, II, and UWB $(3.1-10.6 \mathrm{GHz})[1]$. Out of all the above-mentioned wireless systems, ultra-wide bandwidth (UWB) wireless technology is most sought for very high-data-rate and short-range wireless communication systems, coding for security and low probability of interception, rejection of multipath effect, modern radar systems, and so forth. As mentioned above, this technology uses ultra-wide bandwidth of $7.5 \mathrm{GHz}$, ranging from $3.1 \mathrm{GHz}$ to $10.6 \mathrm{GHz}$.

Planar and printed monopole antennas are the good candidates for use in UWB wireless technology because of their wide impedance bandwidth and nearly omnidirectional azumuthal radiation pattern. Many shapes of planar, also known as planar disc, monopole antennas are reported, which yield very large bandwidth [2-8]. Some of these reported configurations have bandwidth in excess of that required for UWB applications [3]. But, the planar disc configurations are not the most preferred one for these applications, because they are generally mounted on large ground plane, which are perpendicular to the plane of monopole (which makes them three-dimensional structure). Also, the large size ground plane limits the radiation pattern to only half hemisphere. On the other hand, printed monopole antennas (PMAs) are truly planar and have radiation patterns similar to that of a dipole antenna. These monopoles can be integrated with other components on printed circuit board, have reduced size on dielectric substrate, are without backing ground plane and are easy to fabricate. Printed antennas, commonly fabricated on FR4 substrate, are very cost effective, which is ideally suited for UWB technology-based low-cost systems [9-18].

In this paper, design of all the regular geometries of PMA with various feed positions is discussed. Formulae to calculate the lower band-edge (VSWR $=2$ ) frequency for all these printed monopoles are presented. For various feed configurations, frequency-dependent design curves have been generated for $50 \Omega$ microstrip feed line, which yields maximum bandwidth for a given lower band-edge frequency. These design curves, which cover the lower band-edge frequency of $3.1 \mathrm{GHz}$ for UWB applications, are also valid for coplanar feed lines. A systematic study is presented to explain as to how bandwidth increases with increase in lateral dimension of patch giving the example of an elliptical 
geometry. The theoretical study of all the configurations has been carried out using HP high-frequency structure simulator (HP HFSS) [19]. All these results are validated with experiments and reported data.

\section{DESIGN CONSIDERATIONS OF ANTENNAS FOR UWB TECHNOLOGY}

Some of the main features required for antennas for the application of UWB technology are as follows.

(i) It should have bandwidth ranging from $3.1 \mathrm{GHz}$ to 10.6 GHz in which reasonable efficiency and satisfactory omnidirectional radiation patterns are necessary.

(ii) In this ultra-wide bandwidth, an extremely lowemission power level should be ensured. In 2002, the Federal Communication Commission (FCC) has specified the emission limits of $-41.3 \mathrm{dBm} / \mathrm{MHz}$.

(iii) The antenna propagates short-pulse signal with minimum distortion over the frequency range.

The first point is the most important one for antenna designers, which translates into the requirement that antenna should have impedance bandwidth ratio of 3.42 : 1 over which VSWR $\leq 2$. Such a high impedance bandwidth is only realised using multiresonance printed monopole antenna, which generally exhibit high pass impedance characteristics. For such broadband antenna, unlike single resonance tuned dipole or monopole antennas, some special design considerations have to be taken into account. Instead of resonance or operating frequency, lower band-edge frequency and total bandwidth achieved become the design parameters for these printed monopole antennas. The lower bandedge frequency depends primarily on maximum height of the monopole, whereas bandwidth of the antenna depends on how impedance of various modes is matched with the microstrip or coplanar feed line. These parameters are discussed in details for all the regular geometries of printed monopole antennas.

\section{PRINTED MONOPOLE ANTENNA DESIGN}

The printed monopole antennas give very large impedance bandwidth with reasonably good radiation pattern in azumuthal plane, which can be explained in the following two ways. The printed monopole antenna can be viewed as a special case of microstrip antenna configuration, wherein the backing ground plane is located at infinity [7]. A patch is fabricated on dielectric substrate (commonly FR4). Beyond the substrate it can be assumed that a very thick air dielectric substrate $\left(\varepsilon_{r}=1\right)$ exists. It makes a microstrip antenna configuration on a thick substrate with $\varepsilon_{r}$ closer to unity, which yields large bandwidth.

Alternatively, printed monopole antennas can be seen as a vertical monopole antenna. A monopole antenna usually consists of a vertical cylindrical wire mounted over the ground plane, whose bandwidth increases with increase in its diameter. A printed monopole antenna can be equated to a cylindrical monopole antenna with large effective diameter. This second analogy has been used to determine

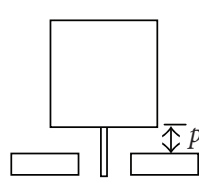

PSMA1

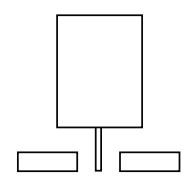

PRMA1

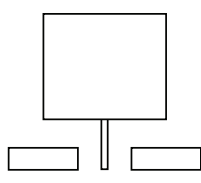

PRMA2

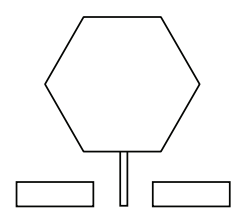

PHMA1

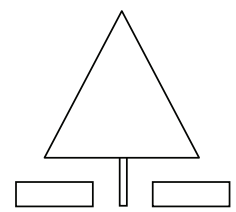

PTMA1 (a)

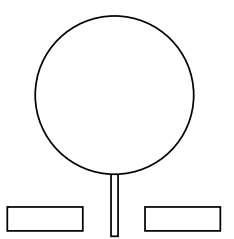

PCMA

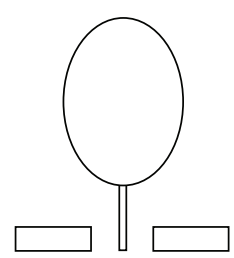

PEMA1

(b)

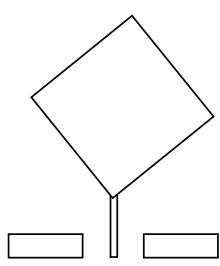

PSMA2

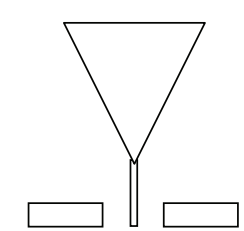

PTMA2

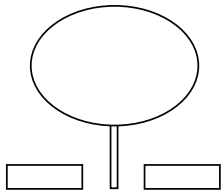

PEMA2

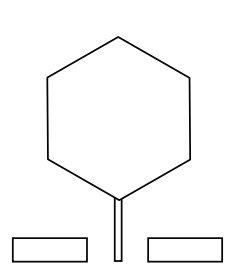

PHMA2 (c)

Figure 1: Various regular-shaped PMAs with different feed configurations.

the lower band-edge frequency of all regular shapes of printed monopole antennas for various feed configurations.

\section{LOWER BAND-EDGE FREQUENCY OF PRINTED MONOPOLE ANTENNAS}

Various regular shaped printed monopole antennas such as printed square monopole antenna (PSMA), printed rectangular monopole antenna (PRMA), printed hexagonal monopole antenna (PHMA), printed triangular monopole antenna (PTMA), printed circular monopole antenna (PCMA), and printed elliptical monopole antenna (PEMA) for different feed positions are shown in Figure 1. For different feed locations, the suffix 1 or 2 , as shown in Figure 1, are put for these monopole antennas. These antennas are generally fabricated on FR4 substrate $\left(\varepsilon_{r}=4.4\right.$, $h=0.16 \mathrm{~cm}$, and $\tan \delta=0.01)$ with backing ground plane 
removed. For patch dimensions, to cover the lower bandedge frequency of around $900 \mathrm{MHz}$, the maximum dimension of the substrate is taken as $9 \mathrm{~cm} \times 9 \mathrm{~cm}$, which becomes almost half when the lower band-edge frequency is doubled [9]. These patches can be fed by $50 \Omega$ microstrip line or by coplanar waveguide. For both these cases, the optimum width of the backside ground plane in the case of microstrip feed or coplanar ground plane is $1 \mathrm{~cm}$. These data are verified through simulation for all the configurations shown in Figure 1.

To estimate the lower band-edge frequency of printed monopole antennas, the standard formulation given for cylindrical monopole antenna can be used with suitable modification [3]. The equation was worked out for the planar monopole antennas. If $L$ is the height of the planar monopole antenna in $\mathrm{cm}$, which is taken same as that of an equivalent cylindrical monopole, and $r$ in $\mathrm{cm}$ is the effective radius of the equivalent cylindrical monopole antenna, which is determined by equating area of the planar and cylindrical monopole antennas, then the lower bandedge frequency is given as [3]

$$
f_{L}=\frac{c}{\lambda}=\frac{7.2}{(L+r+p)} \mathrm{GHz}
$$

where $p$ is the length of the $50 \Omega$ feed line in $\mathrm{cm}$. Unlike the planar disc monopole antennas, the printed configuration has dielectric layer on one side of the monopole. This dielectric material increases the effective dimensions of the monopole leading to reduction in the lower band-edge frequency. This is also confirmed by simulation studies. Hence, more appropriate equation for the lower band-edge frequency is given as

$$
f_{L}=\frac{7.2}{\{(L+r+p) \times k\}} \mathrm{GHz} .
$$

With reference to various configurations in Figure 1, $L$ and $r$ are calculated as follows.

If $S$ is the side length of the PSMA, then

$$
\begin{aligned}
& L=S, \quad r=\frac{S}{2 \pi} \quad \text { for PSMA1, } \\
& L=\sqrt{2} S, \quad r=\frac{S}{2 \sqrt{2} \pi} \quad \text { for PSMA2. }
\end{aligned}
$$

For PRMA, if length $=L$ and width $=W$, then

$$
\begin{array}{ll}
L=L, \quad r=\frac{W}{2 \pi} & \text { for PRMA1 } \\
L=W, \quad r=\frac{L}{2 \pi} & \text { for PRMA2. }
\end{array}
$$

For PTMA, if the side length is $T$, then the values of $L$ and $r$ of the effective cylindrical monopole are determined for both PTMA1 and PTMA2 as

$$
L=\frac{\sqrt{3} T}{2}, \quad r=\frac{T}{4 \pi} .
$$

Similarly, for the PHMA with side length $H$, the $L$ and $r$ values of the equivalent cylindrical monopole antenna are obtained by equating their areas as follows:

$$
\begin{aligned}
& L=\sqrt{3} H, \quad r=\frac{3 H}{4 \pi} \quad \text { for PHMA1, } \\
& L=2 H, \quad r=\frac{3 \sqrt{3} H}{8 \pi} \quad \text { for PHMA2. }
\end{aligned}
$$

For PCMA with radius $A$, values of $L$ and $r$ of the equivalent cylindrical monopole antenna are given by $L=2 A$ and $r=$ A/4.

Finally, for PEMA with semimajor axis $=A$ and semiminor axis $=B$, the $L$ and $r$ of the effective cylindrical monopole are determined as

$$
\begin{array}{lll}
L=2 A, & r=\frac{B}{4} & \text { for PEMA1, } \\
L=2 B, & r=\frac{A}{4} & \text { for PEMA2. }
\end{array}
$$

As discussed earlier, PMA can be thought of as a variation of microstrip antenna, in which the ground plane is considered to be located at infinity. Following this analogy, the factor $k$ in (2) can be thought of as having similar significance as $\sqrt{\varepsilon_{\text {eff }}}$. For commonly used FR4 substrate with $\varepsilon_{r}=4.4$ and $h=0.159 \mathrm{~cm}$, the empirical value of $k=1.15$ estimates lower band-edge frequency within 10\%. Equation (2) with $k=1.15$ has been validated for various reported PMA configurations. For example, a PRMA with dimension $L=3.0 \mathrm{~cm}, W=2.0 \mathrm{~cm}$, and $p=0.2 \mathrm{~cm}$ with $\varepsilon_{r}=4.4$ in [16] has measured value of $f_{L}=1.59 \mathrm{GHz}$, whereas (2) yields the value of $1.77 \mathrm{GHz}$. For second reported PRMA with dimension $L=1.15 \mathrm{~cm}, W=1.2 \mathrm{~cm}$, and $p=0.15 \mathrm{~cm}$ with $\varepsilon_{r}=3.38$, simulated $f_{L}$ is $4.22 \mathrm{GHz}$ [17], against the calculated value of $4.199 \mathrm{GHz}$ using (2). Similarly, the values of frequency calculated using (2) with $k=1.15$ for PEMA tally very well with measured values reported in $[12,13]$. For the dimension $A=8.6 \mathrm{~mm}, B=7.31 \mathrm{~mm}$, and $p=$ $0.5 \mathrm{~mm}$ in [12], the reported measured value of frequency is $3.17 \mathrm{GHz}$, whereas (2) yields the value of $3.206 \mathrm{GHz}$. The reported measured value of frequency for the dimension of $A=10 \mathrm{~mm}, B=10 \mathrm{~mm}$, and $p=1 \mathrm{~mm}$ is $2.7 \mathrm{GHz}$ [13], against the calculated value of $2.664 \mathrm{GHz}$ using (2). Thus, (2) provides starting point for the design of PMAs.

Another important parameter, which decides the lower band-edge frequency as shown in (2), is the length of 50 $\Omega$ feed line $p$. This feed probe length, the bottom contour of the printed monopole patch and the ground plane, three together form the impedance matching network at multiple adjacent resonances of the patch simultaneously. This leads to an increase in bandwidth. Therefore, for different bottom shapes of the patches, the feed length $p$ will be different. Based on this criterion, the various regular shaped patches have been grouped in three categories in Figure 1. In Figure 1(a), the feed transmission line sees abrupt straight edge of the patch shape like PSMA, PRMAs, PTMA, and PHMA. Second category, as shown in Figure 1(b), consists of patches like PCMA and PEMAs having smooth transition 


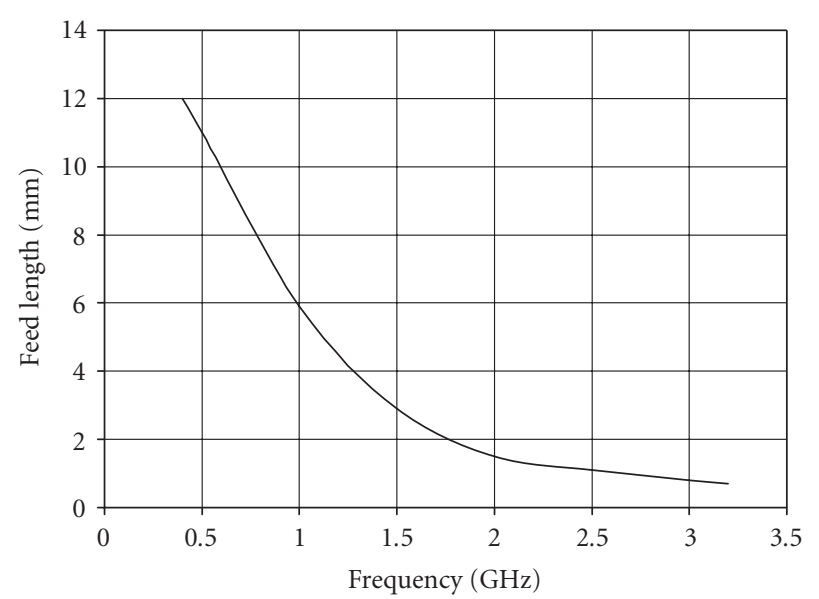

Figure 2: Variation of feed length $p$ with lower band-edge frequency $f_{L}$ for PMAs shown in Figure 1(a).

between transmission line and the curved bottom of the patch. In the third category, as shown in Figure 1(c), transition takes place through bottom corner of the patch and feed transmission line. The value of $p$, for lower bandedge frequency with maximum bandwidth, for these three categories has been discussed here.

To generate design data for the $50 \Omega$ feed line length $p$, for different $f_{L}$, to obtain maximum bandwidth for all the PMAs under three categories were designed using (2) for various values of $f_{L}$ starting from $0.5 \mathrm{GHz}$ to $3.1 \mathrm{GHz}$. This frequency range covers lower band-edge frequency of all the communication channels including that of UWB technology. The value of $p$ for each case for every printed configuration has been optimised to obtain maximum bandwidth using HP HFSS software. The optimised value of $p$, for given $f_{L}$ and maximum bandwidth, is almost same for all the five configurations under category of Figure 1(a). These values of $p$ versus $f_{L}$ are plotted in Figure 2. For maximum bandwidth, when $f_{L}$ increases from $0.5 \mathrm{GHz}$ to $3.1 \mathrm{GHz}$, the value of $p$ decreases from $12 \mathrm{~mm}$ to about $0.7 \mathrm{~mm}$. Though these five configurations were optimised for maximum bandwidth, the highest bandwidth ratio obtained was around $2.7: 1$. This is a relatively moderate bandwidth ratio, which is attributed to the discontinuity at the junction of a feed point, where the feed line abruptly gets truncated by a straight base of the PMAs. Figure 3 shows the variation of $p$ with $f_{L}$ for the second category of PMAs, which includes PCMA and both PEMAs as shown in Figure 1(b). For this case also, as $f_{L}$ increases, feed length $p$ reduces, but magnitude of $p$ is an order less as compared to that of PMAs under the first category. Here, when $f_{L}$ increases from $0.5 \mathrm{GHz}$ to $3.1 \mathrm{GHz}$, the value of $p$ decreases from $1.8 \mathrm{~mm}$ to about $0.12 \mathrm{~mm}$. These design curves on $p$ are validated with measurements and reported results. The optimum value of $p=0.3 \mathrm{~mm}$ reported for PCMA at $f_{L}=2.69 \mathrm{GHz}$ is exactly same as read from Figure 3 [9]. This category of PMAs gives maximum bandwidth. The three PMAs under third categories, that is, vertex fed PMAs, as shown in Figure 1(c), did not exhibit same behaviour with respect to one another. However, for

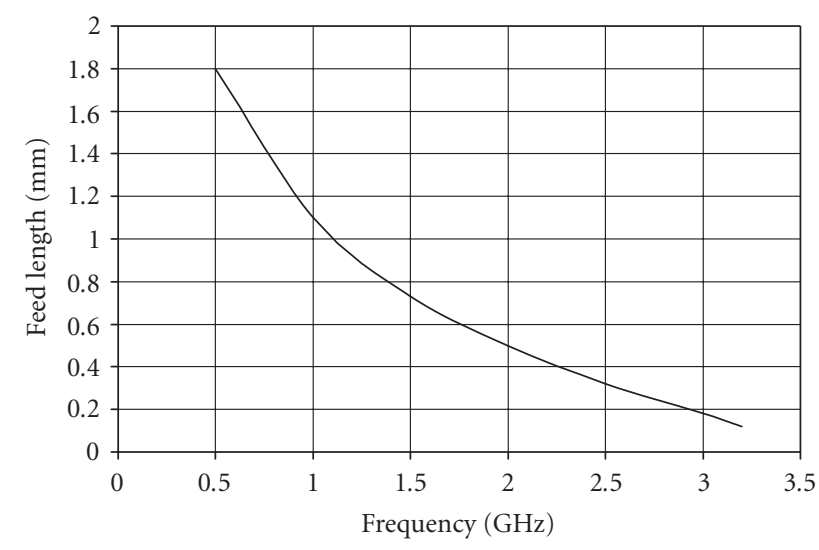

FIgURE 3: Variation of feed length $p$ with lower band-edge frequency $f_{L}$ for PCMA and PEMAs.

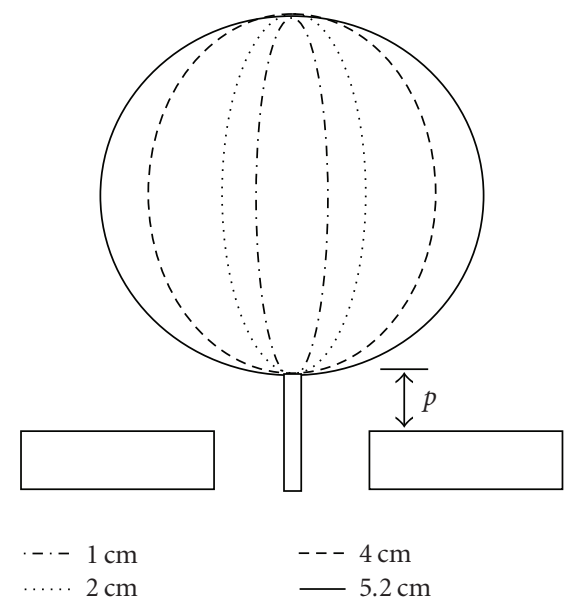

Figure 4: PEMAs with $2 A=4.8 \mathrm{~cm}$ and $2 B$ equal to $(---) 1 \mathrm{~cm}$, $\left.(--)^{-}\right) 2 \mathrm{~cm},(---) 4 \mathrm{~cm}$, and (-) $5.2 \mathrm{~cm}$.

some cases, the value of $p$ versus $f_{L}$ is closer to those of PMAs under second categories than those of first categories. The values of $p$ as shown in Figures 2 and 3 are for the microstrip feed which has been found exactly the same for coplanar waveguide feed as well.

\section{ULTRA-WIDE BANDWIDTH OF A PEMA}

The PMA, as discussed earlier, is viewed as an equivalent thick cylindrical monopole antenna. In the radiating metallic patch, various higher order modes get excited. With optimum feed and increased lateral dimension (i.e., larger width of the patch) all the modes will have larger bandwidth, hence will undergo smaller impedance variation. The shape and size of these planar antennas can be optimised to bring in impedance of all the modes within VSWR $=2$ circle in the Smith chart, leading to very large impedance bandwidth. This has been demonstrated taking the example of PEMA. 


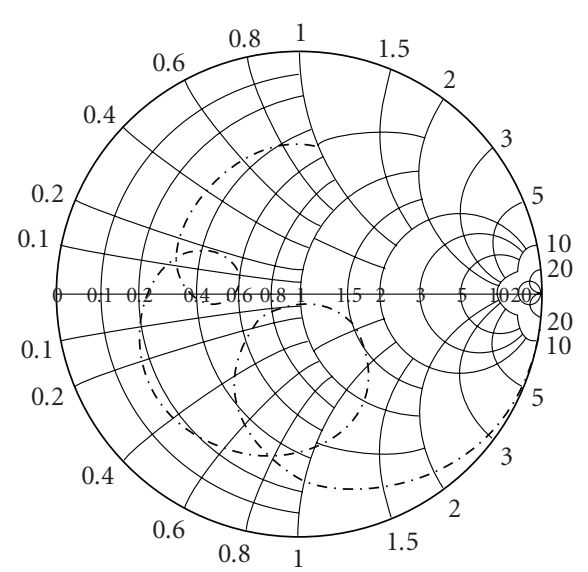

(a)

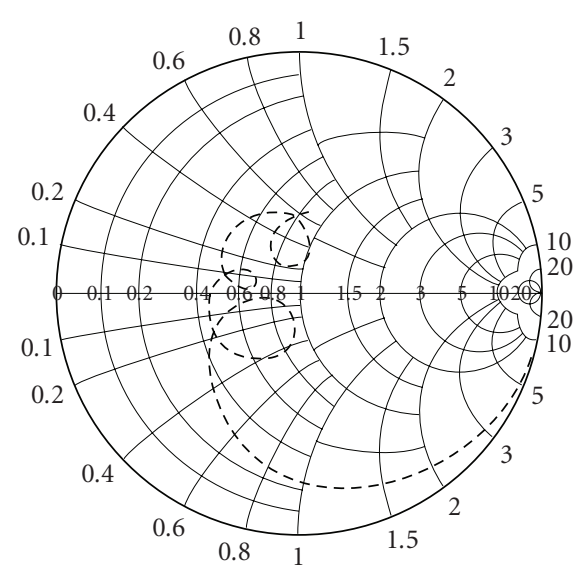

(c)

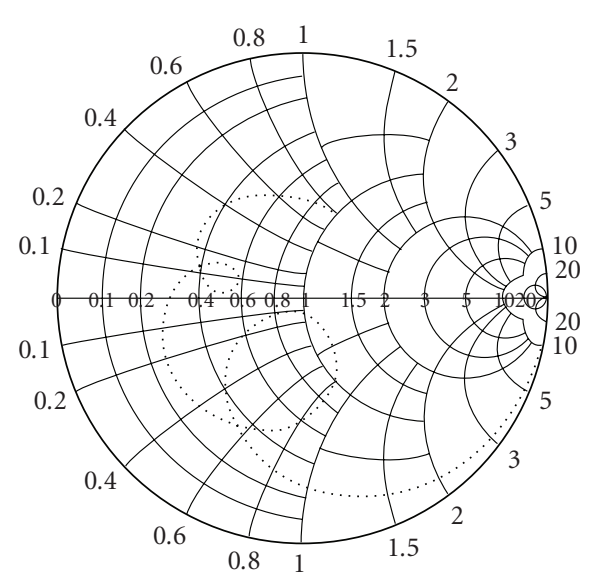

(b)

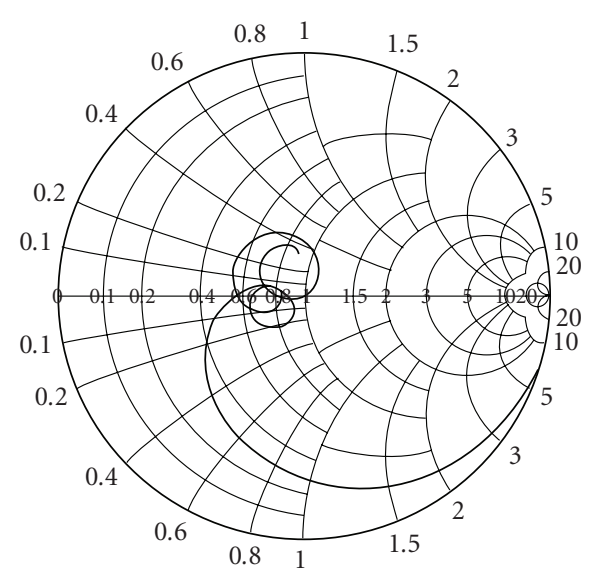

(d)
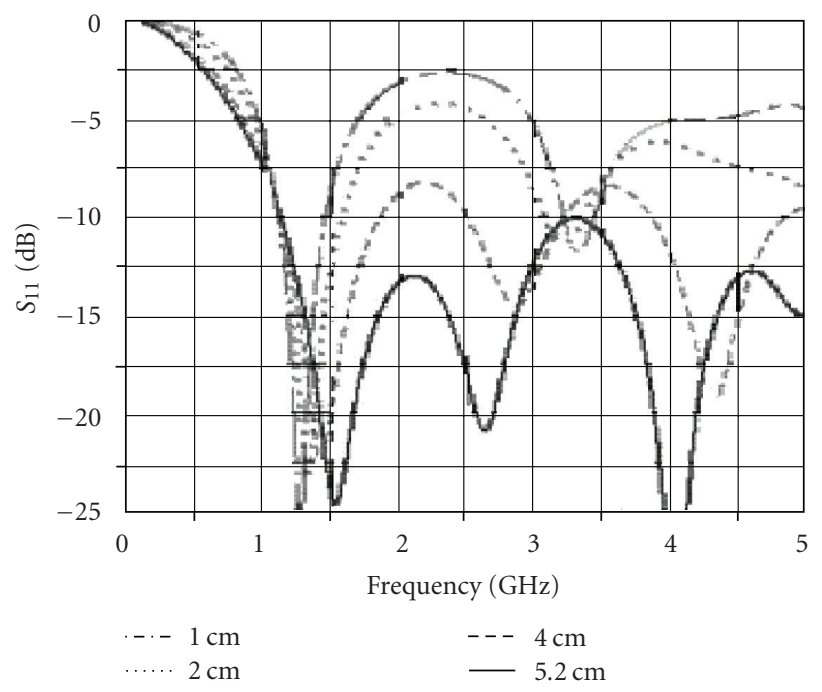

(e)

Figure 5: Impedance loci and return loss plot of four PEMAs with $2 A=4.8 \mathrm{~cm}$ and $2 B$ equal to $(---) 1 \mathrm{~cm},(----) 2 \mathrm{~cm},(---) 4 \mathrm{~cm}$, and $(-) 5.2 \mathrm{~cm}$. 


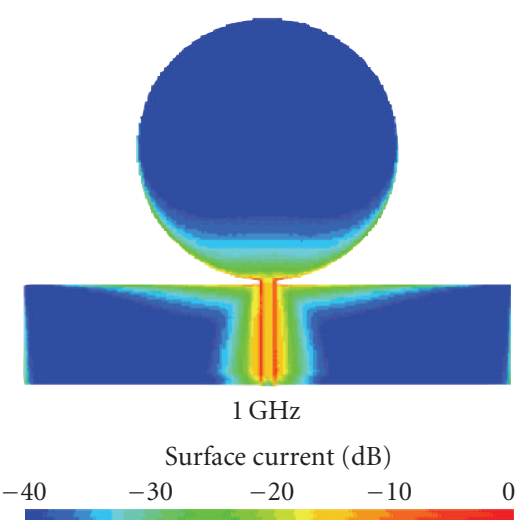

(a)

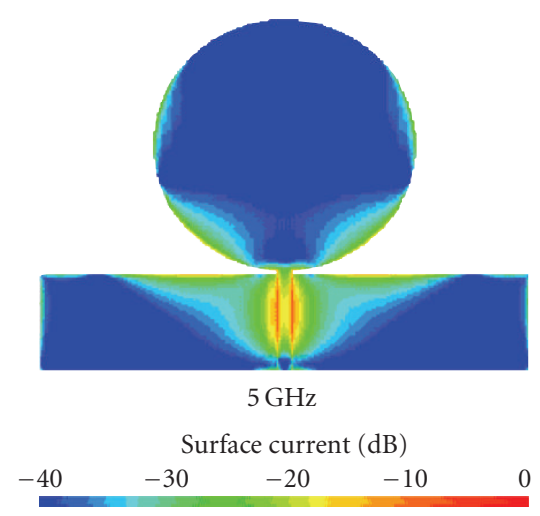

(c)

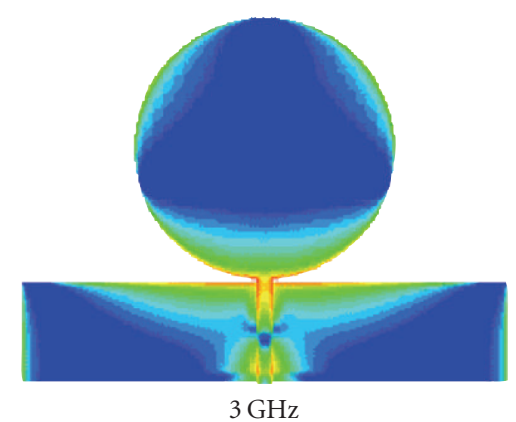

Surface current $(\mathrm{dB})$

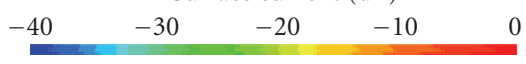

(b)

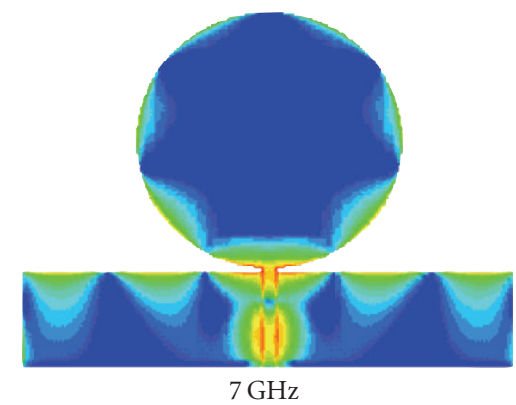

Surface current $(\mathrm{dB})$

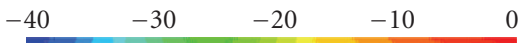

(d)

Figure 6: Simulated current distributions of a PEMA at $1 \mathrm{GHz}, 3 \mathrm{GHz}, 5 \mathrm{GHz}$, and $7 \mathrm{GHz}$.

The PEMAs were designed on FR4 substrate $\left(\varepsilon_{r}=4.4\right.$, $h=0.16 \mathrm{~cm}$, and $\tan \delta=0.01)$ for $f_{L} \sim 1.1 \mathrm{GHz}$. The value of $p$ for this $f_{L}$ as read from Figure 3 is $1 \mathrm{~mm}$. The height of the PEMA is kept fixed at $2 A=4.8 \mathrm{~cm}$ so that the $f_{L}$ remains almost the same. To bring out the variation of input impedance and hence the bandwidth with increased lateral dimension of PEMA, four different values of $2 B$ were chosen as $1 \mathrm{~cm}, 2 \mathrm{~cm}, 4 \mathrm{~cm}$, and finally $5.2 \mathrm{~cm}$. These configurations are shown in Figure 4. These four PEMAs were analysed using HP HFSS software up to the maximum frequency range of $5 \mathrm{GHz}$. These results in the form of impedance loci in Smith chart and corresponding return loss plots are shown in Figure 5. It is noted from Smith chart in Figure 5(a) that for $2 B=1 \mathrm{~cm}$, the PEMA behaves as a thin strip monopole antenna, which is equivalent to thin wire monopole. Here, impedance variation around and in between various loops, which indicates different modes of the elliptical patch, is large, leading to very less impedance bandwidth. As $2 B$ increases, the impedance variation around and in between various modes reduces, bringing smaller loops closer to each other yielding increased bandwidth. This effect is clearly seen in impedance loci plots of Figures 5(b) to 5(d) for $2 B=2.0 \mathrm{~cm}$ to $5.2 \mathrm{~cm}$. The increased bandwidth can be read from the corresponding return loss plot of Figure 5(e). For

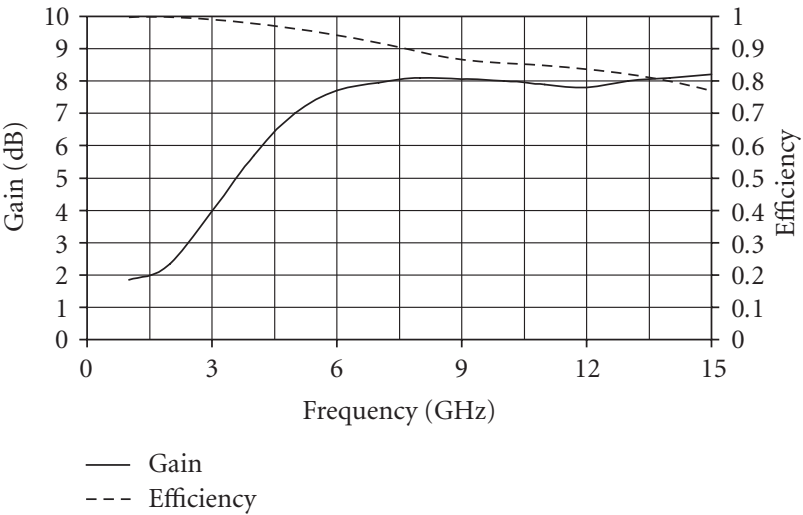

Figure 7: Variation of gain and efficiency of a PEMA with $2 A=$ $4.8 \mathrm{~cm}$ and $2 B=5.2 \mathrm{~cm}$.

$2 B=5.2 \mathrm{~cm}$, all the loops curl around the centre of the Smith chart, bringing them inside VSWR $=2$ circle. This leads to increase in bandwidth beyond $5 \mathrm{GHz}$. For the fourth case of $2 A=4.8 \mathrm{~cm}$ and $2 B=5.2 \mathrm{~cm}$, the PEMA was analysed up to $16 \mathrm{GHz}$.

For this optimised configuration of PEMA, the simulated surface current distributions at four frequencies are shown 


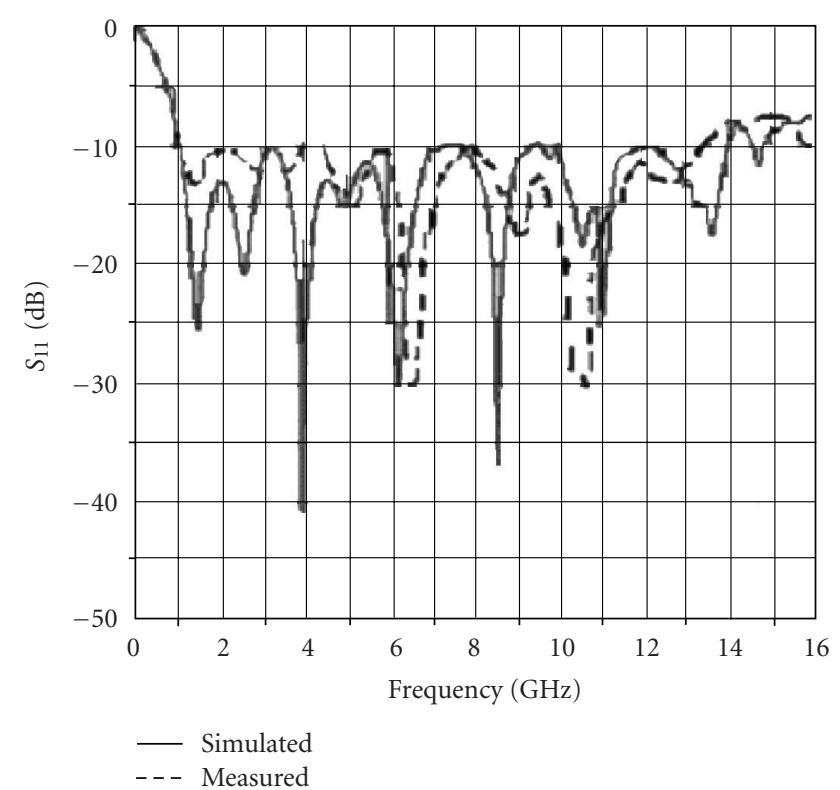

Figure 8: Return loss plots of a PEMA with $2 A=4.8 \mathrm{~cm}$ and $2 B=$ $5.2 \mathrm{~cm}(-)$ simulated, (-- ) measured.

in Figure 6. Figure 6(a) shows the current distribution on the patch near the first resonance at $1 \mathrm{GHz}$. The current is distributed mainly along the edges and the feed point. Along the periphery of the PEMA, there is one half-cycle variation of current, which indicated the fundamental mode. On the ground plane, the current is distributed mainly on the upper edge. This explains the importance of an optimised dimension of the ground plane. The current distribution at $3 \mathrm{GHz}$ has three times more variation as that at $1 \mathrm{GHz}$. Similarly, current distribution at 5 and $7 \mathrm{GHz}$ is also shown in Figure 6. With increase in frequency, the current distribution has more half-cycle variations but with reduced amplitude and confines to the outer boundaries of the patch. The gain and efficiency of this antenna is plotted in Figure 7. The value of gain increases linearly and then saturates, while the efficiency decreases from $100 \%$ to approximately $80 \%$ for the frequency range from $1 \mathrm{GHz}$ to $15 \mathrm{GHz}$. The gain increases from $1.84 \mathrm{~dB}$ to around $7.7 \mathrm{~dB}$ for the variation of frequency from $1 \mathrm{GHz}$ to $6 \mathrm{GHz}$ because of increase in effective area with frequency. Later, the increase is only approximately $0.5 \mathrm{~dB}$ for 6 to $15 \mathrm{GHz}$ because of decreased efficiency. There is less current variation and hence impedance variation between various modes of the PEMA, which also leads to partial filling of nulls in the radiation pattern at higher order modes. Therefore, in complete bandwidth, the elevation and azumuthal radiation patterns remain qualitatively similar to that of the cylindrical monopole antenna. At lower frequencies, azimuthal radiation patterns are close to omnidirectional, whereas in elevation it is a figure of eight because of the very small ground plane. At higher frequencies, radiation patterns in both the planes remain similar to those at lower frequencies with more variations in the elevation plane. Moreover, these PMAs being asymmetrical configurations in two perpendicular planes, perfect omni- directional azumuthal radiation pattern is not achieved and also cross-polar levels are high. Cross-polar levels are approximately $15 \mathrm{~dB}$ down as compared to corresponding copolar levels at lower frequencies, which become only around $5 \mathrm{~dB}$ down at highest frequency of the bandwidth. The configuration was fabricated and tested for the bandwidth. Simulated and measured $S_{11}$ plots are compared in Figure 8 . There is good agreement between the two plots. The measured bandwidth is from $1.1 \mathrm{GHz}$ to $13.5 \mathrm{GHz}$ against the simulated bandwidth of $1.06 \mathrm{GHz}$ to $14.1 \mathrm{GHz}$.

\section{CONCLUSION}

Multiresonance printed monopole antennas are being used increasingly for applications of UWB technology because of their attractive features. Some of the design aspects of these antennas have been discussed in this paper. A systematic study has been presented to explain ultra-wide impedance bandwidth obtained from an elliptical monopole antenna.

\section{ACKNOWLEDGMENTS}

The author would like to acknowledge the help received from Y. Ranga, S. Tewari, M. D. Pandey, and M. K. D. Ulaganathan.

\section{REFERENCES}

[1] Z. N. Chen and M. Y. W. Chia, Broadband Planar Antennas: Design and Applications, John Wiley \& Sons, Chichester, UK, 2006.

[2] M. Hammoud, P. Poey, and F. Colombel, "Matching the input impedance of a broad band disc monopole," Electronics Letters, vol. 29, no. 4, pp. 406-407, 1993.

[3] N. P. Agrawall, G. Kumar, and K. P. Ray, "Wide-band planar monopole antennas," IEEE Transactions on Antennas and Propagation, vol. 46, no. 2, pp. 294-295, 1998.

[4] H. G. Schantz, "Planar elliptical element ultra-wideband dipole antennas," in Proceedings of the IEEE Antennas and Propagation Society International Symposium, vol. 3, pp. 4447, San Antonio, Tex, USA, June 2002.

[5] K. P. Ray, G. Kumar, and P. V. Anob, "Wideband circular wire mesh and annular ring monopole antennas," Microwave and Optical Technology Letters, vol. 48, no. 12, pp. 2459-2461, 2006.

[6] K. P. Ray, G. Kumar, and P. V. Anob, "Wide band planar modified triangular monopole antennas," Microwave and Optical Technology Letters, vol. 49, no. 3, pp. 628-632, 2007.

[7] K. P. Ray, P. V. Anob, R. Kapur, and G. Kumar, "Broadband planar rectangular monopole antennas," Microwave and Optical Technology Letters, vol. 28, no. 1, pp. 55-59, 2001.

[8] G. Kumar and K. P. Ray, Broad Band Microstrip Antennas, Artech House, Boston, Mass, USA, 2003.

[9] J. Liang, C. C. Chiau, X. Chen, and C. G. Parini, "Study of a printed circular disc monopole antenna for UWB systems," IEEE Transactions on Antennas and Propagation, vol. 53, no. 11, pp. 3500-3504, 2005.

[10] Q. Ye and W. R. Lauber, "Microstrip ultra-wideband dipole antenna simulation by FDTD," in Proceedings of the IEEE Antennas and Propagation Society International Symposium, vol. 3, pp. 620-623, Columbus, Ohio, USA, June 2003. 
[11] J.-P. Zhang, Y.-S. Xu, and W.-D. Wang, "Ultra-wideband microstrip-fed planar elliptical dipole antenna," Electronics Letters, vol. 42, no. 3, pp. 144-145, 2006.

[12] K. C. L. Chan, Y. Huang, and X. Zhu, "A planar elliptical monopole antenna for UWB applications," in Proceedings of the IEEE/ACES International Conference on Wireless Communications and Applied Computational Electromagnetics, pp. 182185, Honolulu, Hawaii, USA, April 2005.

[13] C.-Y. Huang and W.-C. Hsia, "Planar elliptical antenna for ultra-wideband communications," Electronics Letters, vol. 41, no. 6, pp. 296-297, 2005.

[14] K. P. Ray and Y. Ranga, "Ultra-wideband printed modified triangular monopole antenna," Electronics Letters, vol. 42, no. 19, pp. 1081-1082, 2006.

[15] K. P. Ray, Y. Ranga, and P. Gabhale, "Printed square monopole antenna with semicircular base for ultra-wide bandwidth," Electronics Letters, vol. 43, no. 5, pp. 263-265, 2007.

[16] M. John and M. J. Ammann, "Optimization of impedance bandwidth for the printed rectangular monopole antenna," Microwave and Optical Technology Letters, vol. 47, no. 2, pp. 153-154, 2005.

[17] H. A.-S. Mohamed, A. E. Abdelnasser, Z. E. Atef, and E. S. Charles, "Design of wideband printed monopole antenna using WIPL-D," in Proceedings of the 20th Annual Review of Progress in Applied Computational Electromagnetics (ACES '04), Syracuse, NY, USA, April 2004.

[18] M. Ferrando-Bataller, M. Cabedo-Fabrés, E. Antonino-Daviu, and A. Valero-Nogueira, "Overview of planar monopole antennas for UWB applications," in Proceedings of the European Conference on Antennas and Propagation (EuCAP '06), Nice, France, November 2006.

[19] HP high frequency structure simulator HP HFSS, version 5., 1999. 

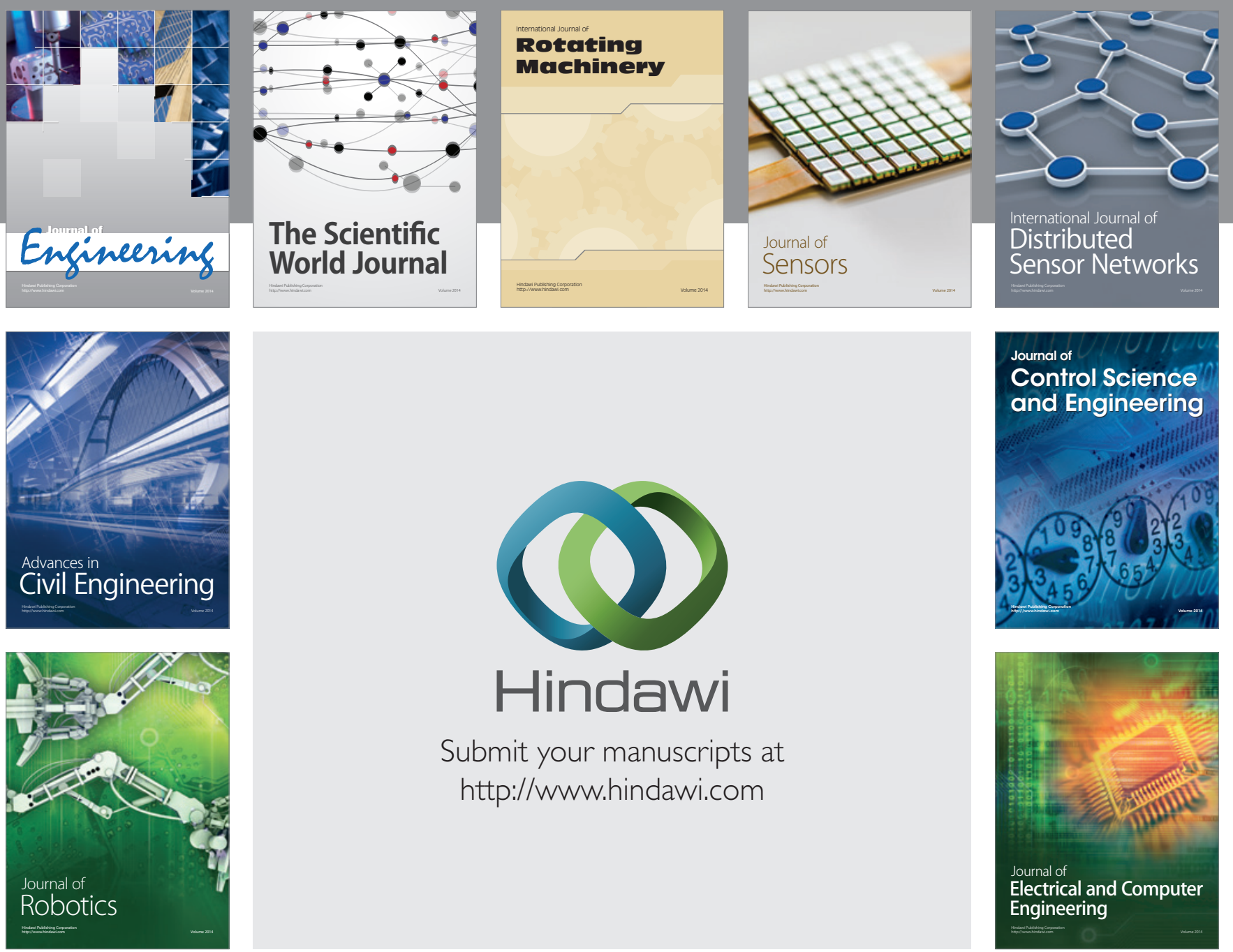

Submit your manuscripts at

http://www.hindawi.com
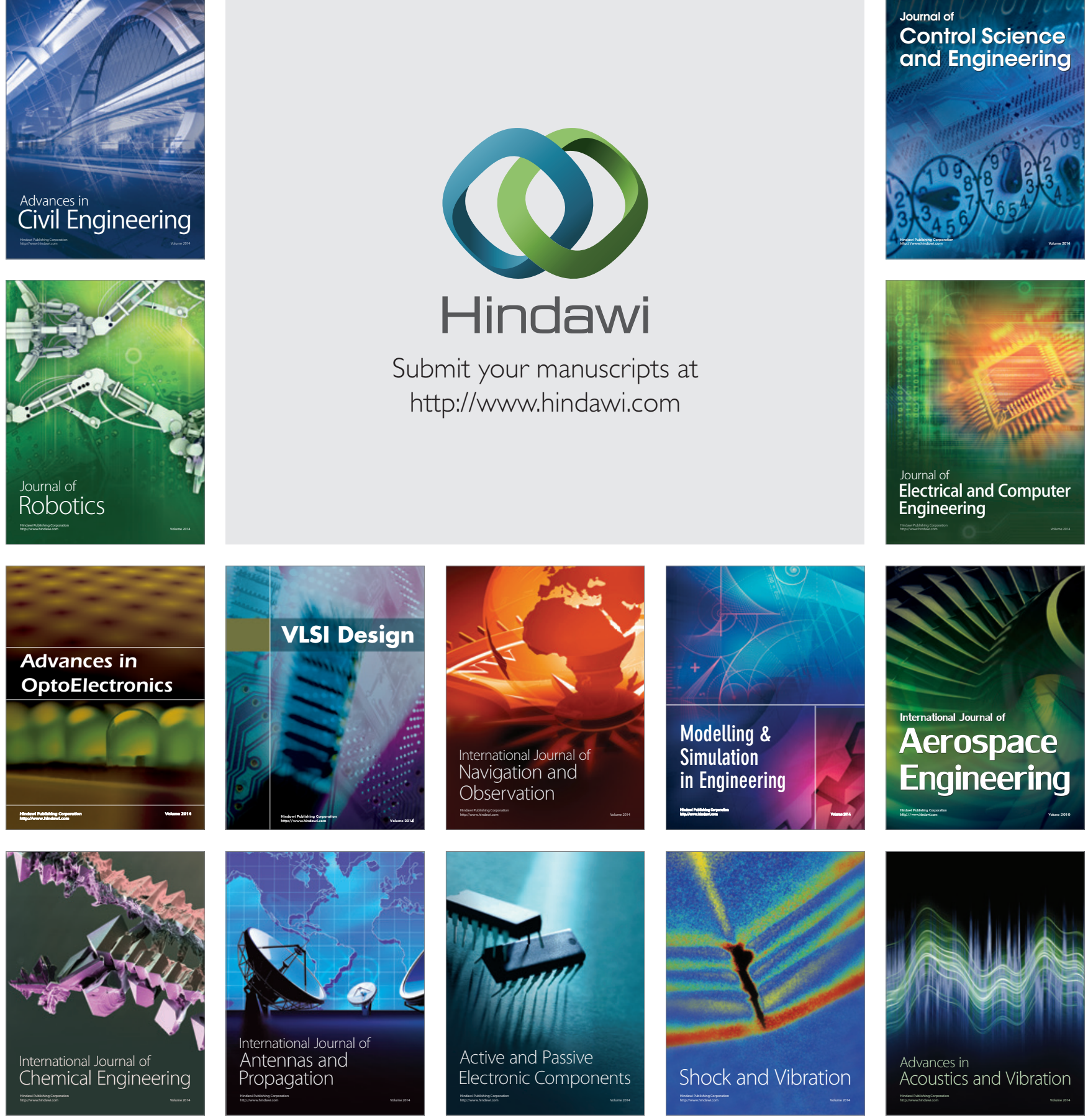